Г. П. Геранюшкина

Байкальский государственный университет, г. Иркутск, Российская Федерация

Т. М. Щеголева

Иркутский государственный университет, 2. Иркутск, Российская Федерация

Д. П. Сковитина

Иркутский государственный университет, г. Иркутск, Российская Федерация

\title{
ПСИХОСЕМАНТИЧЕСКИЙ АНАЛИЗ ЦЕННОСТЕЙ СТУДЕНТОВ РАЗЛИЧНЫХ ЯЗЫКОВЫХ ГРУПП
}

\begin{abstract}
АНнотАция. Представлены результаты психосемантического анализа ценностей студентов, принадлежащих к разноязычным группам: студентов из России, Республики Беларусь, Китайской Народной Республики, Республики Корея. Приведены результаты выявленных различий содержания таких ценностей, как «семья», «свобода», «образование», «справедливость», «любовь», «дружба», «братство», «истина». Также обсуждаются результаты, полученные при помощи методики семантического дифференциала для диагностики психосемантического содержания группы ценностей, выделенной студентами разных стран. Выделены ценности, выступающие значимыми категориями в сознании участников исследования, расхождение в которых может провоцировать возникновение разногласий в молодежной среде. Определены возможности продолжения исследования в более детальном изучении психосемантических особенностей ценностей представителей различных языковых групп.
\end{abstract}

кЛЮЧЕВЫЕ СЛОВА. Ценности; психосемантический подход; психосемантика; психолингвистика; смысл; ценностно-смысловая сфера личности.

ИНФОРМАЦИЯ О СТАТЬЕ. Дата поступления 10 октября 2017 г.; дата принятия к печати 19 декабря 2017 г.; дата онлайн-размещения 29 декабря 2017 г.

G. P. Geranyushkina Baikal State University, Irkutsk, Russian Federation

T. M. Schegoleva

Irkutsk State University, Irkutsk, Russian Federation

D. P. Skovitina

Irkutsk State University, Irkutsk, Russian Federation

\section{PSYCHOSEMANTIC ANALYSIS OF STUDENTS' VALUES OF DIFFERENT LANGUAGE GROUPS}

\begin{abstract}
The results of a psychosemantic analysis of the students' values belonging to multilingual groups are presented: students from Russia, the Republic of Belarus, the People's Republic of China, and the Republic of Korea. The results of the revealed differences in the contents of such values as «family», «freedom», «education», «justice», «love», «friendship», «brotherhood», "truth» are given. Also, the results obtained by using the semantic differential technique for diagnosing the psychosemantic content of a group of values identified by students from different countries are discussed. The values that are identified appear as significant categories in minds
\end{abstract}

\section{Baikal Research Journal}


of the participants of the research, the discrepancy of which may provoke creation of disagreement among the youth. The possibilities for continuing the research in a more detailed study of the psychosemantic value features of different language group representatives are determined.

KEYWORDS. Values; psychosemantic approach; psychosemantics; psycholinguistics; meaning; axiological sphere of personality.

ARTICLE INFO. Received October 10, 2017; accepted December 19, 2017; available online December 29, 2017.

Значительные изменения, происходящие в экономической, социальной и духовной сферах современного общества оказывают существенное влияние на развитие как отдельной личности, так и общества в целом, что неизбежно приводит к перестройке и пересмотру устоев и канонов, сформировавшихся в сознании людей. В связи с эти, одним из перспективных направлений исследования современной личности является анализ ее ценностей, их смыслового содержания, поскольку именно они являются основой для саморегуляции личности и устойчивого существования общества, выступая регуляторами межчеловеческих отношений. В любом обществе, независимо от культуры, найдутся люди, отрицающие ценности любви, семьи или дружбы, в то время как познание, творчество, карьера будут занимать у них лидирующие позиции. Однако мы не можем отрицать, что в каком-либо этническом пространстве существуют ценности, имеющие фундаментальный характер, обуславливающие культуру, восприятие субъектом мира, других, самого себя, а также потребности членов той или иной социальной группы $[1 ; 2]$.

Наблюдая за событиями, происходящими на мировой арене, нельзя не отметить, что наиболее острые конфликты возникают между гражданами, принадлежащими к различной культуре, конфессии или национальности. Подобные расхождения взглядов могут быть связаны с культурно-деятельностной обусловленностью системы значений, которая формируется с первых дней жизни человека в процессе его взаимодействия с другими людьми [3; 4].

Немаловажную роль в понимании и передаче информации играет принадлежность личности к той или иной языковой группе. Отечественная и зарубежная наука не дает однозначного ответа на то, каким образом язык оказывает свое влияние на смысловую составляющую понятий и явлений действительности. Тем не менее, многие авторы придерживаются мнения, что язык систематизирует и структурирует наше мышление, он помогает определить категорию многочисленных объектов мира. Таким образом, ценности обладают субъективно-личностным характером, который формируется в процессе деятельности и представляет собой обобщенное отражение действительности, зафиксированное в форме понятий или значений, которые, в свою очередь, обусловлены культурой того или иного народа. Представленная в виде какого-либо понятия (слова), ценность является отражением общественного опыта, в котором проявляется национальная специфика и национально-культурная ментальность носителя.

Наличие лексических и грамматических различий между языками приводит к трудностям, связанным с взаимопониманием между людьми, передачей информации, трактовке тех или иных понятий.

Многие современные исследователи приходят к выводу о существовании общих фоновых знаний, «кластеров», которые выступают базисом в трактовке понятий, ценностей и явлений представителями различных языковых групп. Влияние субъективных представлений на формирование смыслового содержания ценностей у представителей различных языковых групп очень велико. Нормы, ценности, нашедшие свое отражение в индивидуальном сознании людей, объединенных одной

\section{Baikal Research Journal}

электронный научный журнал Байкальского государственного университета 
языковой группой, в форме представлений и понятий, формируют языковую картину мира, которая влияет на различные аспекты человеческой жизни. В психосемантике картина мира, формируемая субъектом, является индивидуальной моделью отражения действительности, в связи с чем, мы можем сказать, что количество моделей мира пропорционально количеству субъектов. А. Р. Лурия пишет о том, что «человек имеет двойной мир, в который входит и мир непосредственно отражаемых предметов, и мир образов, объектов, отношений и качеств, которые обозначаются словами. Таким образом, слово - это особая форма отражения действительности. Человек может произвольно называть эти образы независимо от их реального наличия, может произвольно управлять этим вторым миром» [5;6].

Структуры индивидуального сознания не дублируют исходное содержание, а дополняют его, устанавливают новые связи, значимые для самого субъекта. Слово представляет собой общественный опыт, который находит свое отражение в значениях. Язык, в свою очередь, дает возможность человеку обращаться к знаниям и опыту предшествующих поколений.

Существование множества языков обуславливает наличие многообразных картин мира, принадлежащих к различным национальным культурам. Языковая картина мира не только влияет на отношение человека к природе, к окружающему миру, к самому себе, но также определяет нормы, ценности, правила и традиции в поведении человека. Представления об аналитической функции языка, об опосредованности восприятия и сознания субъекта системой значений и факт различия национальных языков по лексической семантике и грамматической структуре приводит к выводу о различии картин мира, формируемых у представителей различных языковых культур. В. Гумбольдт считал, что «различные языки - это не различные обозначения одного о того же предмета, а разные видения его» .

Опираясь на данное утверждение, можно предположить, что существенные различия в понимании и трактовке общепринятых ценностей угрожают возникновением межэтнических, межгосударственных и религиозных противоречий и конфликтов. Важно отметить, что зарождение подобных разногласий очень часто происходит в молодежной среде как наиболее общественно активной и нестабильной части населения [7]. В современной переходной ситуации необходимо уделять особое внимание группе данного возрастного диапазона, поскольку молодежь является поколением, призванным придти на смену родителям и стать опорой для общества и государства. В связи с этим молодежь, как возрастная группа, является наиболее перспективной для исследования психосемантического содержания различных категорий ценностей.

Теоретико-методологической основой нашего исследования является культурно-историческая теория Л. С. Выготского; теоретические положения проблемы сознания, значения, смысла, положенные в основу психосемантического направления в психологии (Л. С. Выготский, С. Л. Рубинштейн А. Н. Леонтьев, А. А. Леонтьев, Д. А. Леонтьев, Б. С. Братусь) [4; 8; 9]. В разработке теоретической основы работы мы опирались на труды В. Ф. Петренко, Е. Ю. Артемьевой, В. В. Столина, О. В. Митиной, А. Г. Шмелева, А. А. Нистратова, В. И. Похилько, посвященные вопросу психосемантики $[10 ; 11 ; 12 ; 13]$.

Целью нашего исследования являлся психосемантический анализ ценностей студентов различных языковых групп. В качестве гипотезы исследования нами было выдвинуто предположение о том, что психосемантическое содержание ценностей студентов, принадлежащих к разным языковым группам, имеет свои особенности.

В процессе работы были использованы общенаучные исследовательские методы: теоретический анализ психологической литературы; сравнительно-аналити-

\section{Baikal Research Journal}

электронный научный журнал Байкальского государственного университета 
ческий метод, а также частные психологические методики: методика семантического дифференциала для диагностики восприятия ценностей представителями различных языковых групп $[14,15]$; методика ранжирования ценностей, которая представляет собой процедуру упорядочения объектов, выполняемую лицом, принимающим решение, основанное на своем личном опыте; анкета, в основу которой лег метод определения понятий, направленный на выявление субъективного представления о предложенных ценностях. Статистическая обработка полученных нами данных проводилась при помощи нахождения среднего значения измеряемой величины, дисперсии, среднего квадратического отклонения выборочную совокупность вошло 60 человек, а именно студенты из России, Республики Беларусь, Китайской Народной Республики, Республики Корея. Состав каждой языковой группы был представлен пятнадцатью испытуемыми в возрасте от 18-25 лет. Для исследования китайских и корейских студентов тексты методик, инструкции были подвержены переводу, а также стилистико-смысловой правке носителем языка - переводчика.

Проведенное эмпирическое исследование, направленное на выявление психосемантических особенностей ценностей позволило сделать вывод о наличии различного рода особенностей в трактовке и понимании ценностей среди студентов различных языковых групп. Данные, полученные путем использования методики ранжирования ценностей, позволили выявить, какие ценности являются наиболее значимыми для представителей разноязычных групп. Испытуемыми приоритет был отдан в пользу ценностей, имеющих общечеловеческое признание, а именно таким как «любовь», «семья», «добро», «дети» и «здоровье». Однако, в каждой из групп был отмечен ряд ценностей, который, на наш взгляд, может быть обусловлен историей, традициями, социальными нормами, политическими и религиозными идеями того или иного государства.

Анализ данных показал, что первые десять ранговых мест были отданы таким ценностям, как «семья», «добро», «здоровье», «дети», «любовь», «справедливость», «взаимопонимание», «истина», «образование», «свобода», «красота», «равенство», «карьера», «простота», «братство», «саморазвитие», «дружба», «самодостаточность». Полученные результаты послужили основой для проведения второй части диагностического исследования и вошли в содержание методики определения понятий. В процессе анализа предложенных испытуемым понятий, нами были отобраны ценности, которые обладают наибольшими отличиями по смысловой составляющей. В их число вошли «семья», «свобода», «образование», «справедливость», «любовь», «дружба», «братство», «истина».

В рамках данной статьи мы бы хотели обратить внимание на такие ценности, как «семья» и «справедливость», т.к. результаты их анализа показали наиболее выраженные отличия в их интерпретации представителями различных языковых групп.

В результате проведенного анализа, основанного на выделении общих категорий из числа представленных определений, мы можем сделать вывод, что понимание ценности «семья» схоже между группами китайцев и корейцев. Вероятно, это связано с восточной философией, которая по сей день оказывает влияние на сознание людей. Стоит ответить, что представители Южной Кореи и Китая склонны придерживаться традиционной системы семейных ценностей. Семья, с точки зрения русскоязычных испытуемых, принявших участие в исследовании, не ограничена кровным родством и рождением детей. Семья в понимании русскоязычных студентов может строиться на духовной связи между людьми, целью которой является построение комфортных отношений, основанных на понимании и доверии. Белорусы отличаются яркими эмоциональными внутрисемейными от-

\section{Baikal Research Journal}

электронный научный журнал Байкальского государственного университета 
ношениями, приводящими к крепкому союзу, дружбе и взаимопониманию между поколениями.

Мы можем предположить, что представители России и Республики Беларусь в определении понятия справедливость склонны опираться на категории личностного характера, нежели придерживаться правил и законов, установленных в обществе. Главный судья в восстановлении справедливости - это совесть и честь. Китайские и корейские студенты выстраивают свое отношение к справедливости, отталкиваясь от политики государства и установленных в нем законов и правил поведения.

На основании анализа полученных данных мы можем говорить о наличии расхождений в трактовке ценностей разноязычными испытуемыми. Сформировавшиеся представления в сознании белорусских и русских студентов, относительно рассмотренных нами ценностей, имеют общее основание. Вероятно, это связано со спецификой языка и культурой славянских народов. Представители данных языковых групп отличаются эмоционально-экспрессивной окраской ценностей. Они также склонны приводить больше примеров, опираться на собственный опыт при трактовке предложенных ценностей, что может указывать на открытость и доверие участников исследований. Студенты Республики Корея и Китайской Народной Республики старались быть ограничены в собственных суждениях, что может указывать на осторожное отношение к организованному исследованию. В ответах испытуемых из азиатских стран, на наш взгляд, в полной мере отразилась специфика культуры и философии данных государств, которая, в свою очередь, наложила отпечаток на лексическую и синтаксическую составляющую языка.

Выдвинутые нами предположения были подтверждены данными, полученными при помощи методики семантического дифференциала для диагностики восприятия ценностей. Показатели по фактору «Сила» дали нам возможность увидеть, какие ценности обладают наиболее выраженной эмоциональной окраской (табл. 1).

Сводная таблица данных среднего квадратичного отклонения по фактору "Сила» методики семантического дифференциала

\begin{tabular}{|l|r|r|r|r|r|r|r|r|}
\hline & Любовь & Семья & $\begin{array}{c}\text { Образо- } \\
\text { вание }\end{array}$ & Свобода & $\begin{array}{l}\text { Справед- } \\
\text { ливость }\end{array}$ & Дружба & Истина & Братство \\
\hline $\begin{array}{l}\text { Российские } \\
\text { студенты }\end{array}$ & 2,109 & 1,850 & 2,050 & 1,846 & 2,009 & 1,240 & 2,150 & 1,680 \\
\hline $\begin{array}{l}\text { Студенты республики } \\
\text { Беларусь }\end{array}$ & 2,043 & 2,080 & 1,653 & 1,090 & 2,003 & 1,580 & 1,880 & 1,780 \\
\hline Студенты КНР & 1,906 & 2,001 & 1,717 & 1,123 & 1,507 & 1,300 & 1,570 & 1,870 \\
\hline $\begin{array}{l}\text { Студенты Южной } \\
\text { Кореи }\end{array}$ & 1,757 & 2,127 & 2,530 & 1,259 & 1,696 & 1,440 & 1,690 & 1,764 \\
\hline
\end{tabular}

Анализ результатов по фактору «Активность» позволил обнаружить синестезический перенос испытуемыми различных языковых групп на ценности, которые в их культуре обладают первостепенным характером (табл. 2).

Таблица 2

Сводная таблица данных среднего квадратичного отклонения по фактору "Активность" методики семантического дифференииала

\begin{tabular}{|l|r|r|r|r|r|r|r|r|}
\hline & Любовь & Семья & $\begin{array}{c}\text { Образо- } \\
\text { вание }\end{array}$ & Свобода & $\begin{array}{c}\text { Сраведли- } \\
\text { вость }\end{array}$ & Дружба & Истина & Братство \\
\hline $\begin{array}{l}\text { Российские } \\
\text { студенты }\end{array}$ & 1,860 & 1,700 & 2,080 & 1,683 & 2,057 & 1,880 & 2,140 & 1,688 \\
\hline $\begin{array}{l}\text { Студенты респу- } \\
\text { блики Беларусь }\end{array}$ & 1,763 & 1,624 & 1,723 & 1,509 & 1,980 & 1,780 & 1,860 & 1,800 \\
\hline
\end{tabular}

\section{Baikal Research Journal}


Окончание табл. 2

\begin{tabular}{|l|r|r|r|r|r|r|r|r|}
\hline & Любовь & Семья & $\begin{array}{c}\text { Образо- } \\
\text { вание }\end{array}$ & Свобода & $\begin{array}{c}\text { Справедли- } \\
\text { вость }\end{array}$ & Дружба & Истина & Братство \\
\hline Студенты КНР & 1,629 & 1,875 & 1,847 & 1,227 & 1,839 & 1,590 & 1,683 & 1,990 \\
\hline $\begin{array}{l}\text { Студенты Южной } \\
\text { Кореи }\end{array}$ & 1,506 & 1,907 & 2,169 & 1,309 & 1,797 & 1,480 & 1,700 & 1,880 \\
\hline
\end{tabular}

Исходя из показателей, полученных по фактору «Отношение», мы можем предположить, что выделенные ценности выступают значимыми категориями в сознании участников исследования и расхождения в их представлении могут способствовать возникновению различного рода конфликтов (табл. 3).

Таблица 3

Сводная таблица данных среднего квадратичного отклонения по фактору "Отночение» методики селантического дифференциала

\begin{tabular}{|l|r|r|r|r|r|r|r|r|}
\hline & Любовь & Семья & $\begin{array}{c}\text { Образо- } \\
\text { вание }\end{array}$ & Свобода & $\begin{array}{c}\text { Справед- } \\
\text { ливость }\end{array}$ & Дружба & Истина & Братство \\
\hline $\begin{array}{l}\text { Российские } \\
\text { студенты }\end{array}$ & 2,037 & 1,281 & 2,046 & 2,217 & 1,937 & 1,380 & 1,870 & 1,764 \\
\hline $\begin{array}{l}\text { Студенты республики } \\
\text { Беларусь }\end{array}$ & 2,007 & 1,758 & 1,429 & 1,486 & 1,803 & 1,573 & 1,688 & 1,840 \\
\hline Студенты КНР & 1,803 & 2,160 & 1,617 & 1,213 & 1,763 & 1,690 & 1,700 & 1,920 \\
\hline $\begin{array}{l}\text { Студенты Южной } \\
\text { Кореи }\end{array}$ & 1,729 & 2,253 & 2,053 & 1,403 & 1,697 & 1,730 & 1,760 & 1,890 \\
\hline
\end{tabular}

На основании результатов проведенного исследования мы можем говорить о подтверждении выдвинутой нами гипотезы о том, что психосемантическое содержание ценностей студентов, принадлежащих к разным языковым группам, имеет свои особенности.

Учитывая актуальность представленной проблемы, мы видим возможности ее продолжения в более детальном исследовании психосемантических особенностей ценностей представителей различных языковых групп. Для углубленного изучения данной проблемы мы считаем необходимым увеличение объема исследуемой выборки, которая будет способствовать выделения более общих категорий при анализе ответов испытуемых. Необходимым условием получения объективных данных в процессе проведения исследования является участие в нем группы опытных переводчиков и психологов, выполняющих роль экспертов.

Мы также полагаем, что изучение психосемантических особенностей ценностей иностранных студентов и дальнейший учет их особенностей будет способствовать созданию эффективных международных программ студенческого обмена, усовершенствованию условий образования во внутренней организации вузов страны, выстраиванию более крепких и доверительных отношений в студенческой среде не только на межгрупповом, но и на межличностном уровне.

\section{Список использованной литературы}

1. Леонтьев А. А. Психологические единицы порождения речевого высказывания / А. А. Лентьев. - М. : Наука, 1969. - 307 с.

2. Рокич М. Природа человеческих ценностей / М. Рокич. - М., 1973. - 276 с.

3. Выготский Л. С. Мышление и речь. Психологические исследования / Л. С. Выготский. - М. : Лабиринт, 1996. - 416 с.

4. Леонтьев А. Н. Деятельность. Сознание. Личность / А. Н. Леонтьев. - М. : Политиздат, 1977. - 304 с.

\section{Baikal Research Journal}



$320 \mathrm{c}$.

5. Лурия А. Р. Язык и сознание / А. Р. Лурия. - М. : Изд-во Моск. ун-та, 1979. -

6. Коул М. Культура и мышление. Психологический очерк / М. Коул, С. Скрибнер ; пер. с англ. П. Тульвисте. - М. : Прогресс, 1977. - 261 с.

7. Трофимова Е.Л. Формирование готовности к межкультурному сотрудничеству у студентов в процессе обучения и воспитания в вузе / Е. Л. Трофимова // Сибирский психологический журнал. - 2013. - № 47. - С. 129-139.

8. Леонтьев Д. А. Психология смысла: природа, строение и динамика смысловой реальности / Д. А. Леонтьев. - 2-е изд., перераб. и доп. - М.: Смысл, 2003. - 487 с.

9. Слобин Д. Психолингвистика / Д. Слобин, Дж. Грин ; пер. с англ. Е. И. Негнивичкой. - М. : Прогресс, 1976. - 336 с.

10. Артемьева Е. Ю. Основы психологии субъективной семантики / Е. Ю. Артемьева. - М. : Наука, 1999. - 360 с.

11. Петренко В. Ф. Основы психосемантики / В. Ф.Петренко. - 2-е изд., доп. - СПб. : Питер, 2005. - 480 с.

12. Столин В. В. Психологическое строение образа мира и проблемы нового мышления / В. В. Столин, А. П. Наминач // Вопросы психологии. - 1988. — № 4. - С. 34-46.

13. Шмелев А. Г. Введение в экспериментальную психосемантику / А. Г. Шмелев. М. : Изд-во МГУ, 1982. - 157 с.

14. Осгуд Ч. Приложение методики семантического дифференциала к исследованиям по эстетике и смежным проблемам / Ч. Осгуд, Дж. Суси, П. Танненбаум // Семиотика и искусствометрия / под ред. Ю. М. Лотмана, В. М. Петрова. - М. : Мир, 1972. - С. 278-298.

15. Терехова Т. А. Нарративное интервью как методологический конструкт междисциплинарного качественного исследования / Т. А. Терехова, С. К. Малахаева // Психология в экономике и управлении. - 2013. - № 1 (9). — С. 91-96.

\section{References}

1. Leont'ev A. A. Psikhologicheskie edinitsy porozhdeniya rechevogo vyskazyvaniya [Psychological Units of Speech Act Generation. Moscow]. Moscow, Nauka Publ., 1969. 307 p.

2. Rokeach M. The Nature of Human Values. New York, Free Press, 1973. 438 p. (Russ. ed.: Rokeach M. Priroda chelovecheskikh tsennostei. Moscow, 1973. 276 p.).

3. Vygotskii L. S. Myshlenie i rech'. Psikhologicheskie issledovaniya [Mind and Speech. Psychological Research]. Moscow, Labirint Publ., 1996. 416 p.

4. Leont'ev A. N. Deyatel'nost'. Soznanie. Lichnost' [Activity. Consciousness. Personality]. Moscow, Politizdat Publ., 1977. 304 p.

5. Luriya A. R. Yazyk i soznanie [Language and Consciousness]. Moscow, Lomonosov Moscow State University Publ., 1979. 320 p.

6. Cole M., Scribner S. Culture and thought: A psychological introduction. New York, Wiley, 1974. (Russ. ed.: Cole M., Scribner S. Kul'tura i myshlenie: Psikhologicheskii ocherk. Moscow, Progress Publ., 1977. 261 p.).

7. Trofimova E. L. Formation of Students' Readiness for Intercultural Cooperation in the Course of Training and Education in the Higher Educational Institution. Sibirskii psikhologicheskii zhurnal = Siberian Journal of Psychology, 2013, no. 47, pp. 129-139. (In Russian).

8. Leont'ev D. A. Psikhologiya smysla: priroda, stroenie i dinamika smyslovoi real'nosti [Psychology of Meaning: Nature, Structure and Dynamics of Semantic Reality]. $2^{\text {nd }}$ ed. Moscow, M.: Smysl Publ., 2003. 487 p.

9. Slobin D., Grin Dzh. ; Negnivichkaya E. I. (transl.) Psikholingvistika [Psycholinguistics]. Moscow, Progress Publ., 1976. 336 p.

10. Artem'eva E. Yu. Osnovy psikhologii sub"ektivnoi semantiki [Basis of Psychology of Subjective Semantics]. Moscow, Nauka Publ., 1999. 360 p.

11. Petrenko V. F. Osnovy psikhosemantiki [Basics of Psychosemantics]. $2^{\text {nd }}$ ed. Saint Petersburg, Piter Publ, 2005. 480 p.

12. Stolin V. V., Naminach A. P. Psychological Structure of World Image and Problems of New Thinking. Voprosy psikhologii = Voprosy Psychologii, 1988, no. 4, pp. 34-46. (In Russian).

13. Shmelev A. G. Vvedenie $v$ eksperimental'nuyu psikhosemantiku [Introduction to Experimental Psychology]. Moscow, Lomonosov Moscow State University Publ., 1982. 157 p.

\section{Baikal Research Journal}


14. Osgud Ch., Dzh. Susi, P. Tannenbaum Application of semantic differential technique to research on aesthetics and related problems. In Lotman Yu. M., Petrov V. M. (eds). Semiotika i iskusstvometriya [Semiotics and Artmetry]. Moscow, Mir Publ., 1972, pp. 278298. (In Russian).

15. Terekhova T. A., Malakhaeva S. K. Narrative interview as methodological constructive unit of Interdisciplinary qualitative research. Psikhologiya $v$ ekonomike $i$ upravlenii $=$ Psychology in economics and management, 2013, no. 1 (9), pp. 91-96. (In Russian).

\section{Информация об авторах}

Геранюшкина Галина Петровна - кандидат психологических наук, доцент, кафедра социальной и экономической психологии, социологии и социальной работы, Байкальский государственный университет, 664003, г. Иркутск, ул. Ленина, 11, e-mail: gergp@mail.ru.

Щеголева Талара Михайловна - кандидат психологических наук, доцент, кафедра общей психологии, Иркутский государственный университет, 664003, г. Иркутск, К. Маркca, 1, e-mail: schegoleva52@mail.ru.

Сковитина Дарья Петровна - магистрант, факультет психологии, программа «Психология служебной деятельности», Иркутский государственный университет, 664003, г. Иркутск, К. Маркса, 1, e-mail: d.sckovitina@yandex.ru.

\section{Authors}

Galina P. Geranyushkina - PhD in Psychology, Associate Professor, Chair of Social and Economic Psychology, Sociology and Social Work, Baikal State University, 11 Lenin St., 664003, Irkutsk; e-mail: gergp@mail.ru.

Tamara M.Schegoleva - PhD in Psychology, Associate Professor, Chair of General Psychology, Irkutsk State University, 1 K. Marx St., 664003, Irkutsk; e-mail: schegoleva52@mail.ru.

Daria P. Skovitina - Master's Student, Department of Psychology, Program 'Psychology of Employment Activity', Irkutsk State University, 1 K. Marx St., 664003, Irkutsk; e-mail: d.sckovitina@yandex.ru.

\section{Для цитирования}

Геранюшкина Г. П. Психосемантический анализ ценностей студентов различных языковых групп / Г. П. Геранюшкина, Т. М. Щеголева, Д. П. Сковитина // Baikal Research Journal. — 2017. - T. 8, № 4. — DOI : 10.17150/2411-6262.2017.8(4).6.

\section{For Citation}

Geranyushkina G. P., Schegoleva T. M., Skovitina D. P. Psychosemantic analysis of students' values of different language groups. Baikal Research Journal, 2017, vol. 8, no. 4. DOI: 10.17150/2411-6262.2017.8(4).6. (In Russian).

\section{Baikal Research Journal}

